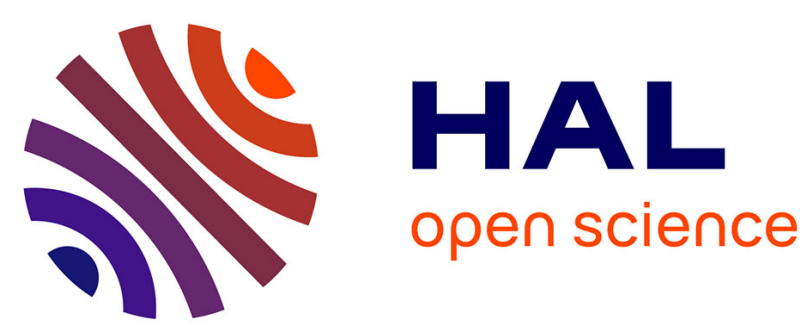

\title{
The Adrenal Cortex and Life
}

Gavin P. Vinson

\section{- To cite this version:}

Gavin P. Vinson. The Adrenal Cortex and Life. Molecular and Cellular Endocrinology, 2009, 300

(1-2), pp.2. 10.1016/j.mce.2008.09.008 . hal-00532077

\section{HAL Id: hal-00532077 \\ https://hal.science/hal-00532077}

Submitted on 4 Nov 2010

HAL is a multi-disciplinary open access archive for the deposit and dissemination of scientific research documents, whether they are published or not. The documents may come from teaching and research institutions in France or abroad, or from public or private research centers.
L'archive ouverte pluridisciplinaire HAL, est destinée au dépôt et à la diffusion de documents scientifiques de niveau recherche, publiés ou non, émanant des établissements d'enseignement et de recherche français ou étrangers, des laboratoires publics ou privés. 


\section{Accepted Manuscript}

Title: The Adrenal Cortex and Life

Author: Gavin P. Vinson

PII:

DOI:

S0303-7207(08)00405-X

Reference: doi:10.1016/j.mce.2008.09.008

MCE 6977

To appear in: $\quad$ Molecular and Cellular Endocrinology

Received date: 29-7-2008

Revised date: $\quad$ 4-9-2008

Accepted date: $\quad$ 5-9-2008

Please cite this article as: Vinson, G.P., The Adrenal Cortex and Life, Molecular and Cellular Endocrinology (2008), doi:10.1016/j.mce.2008.09.008

This is a PDF file of an unedited manuscript that has been accepted for publication. As a service to our customers we are providing this early version of the manuscript. The manuscript will undergo copyediting, typesetting, and review of the resulting proof before it is published in its final form. Please note that during the production process errors may be discovered which could affect the content, and all legal disclaimers that apply to the journal pertain. 


\title{
The Adrenal Cortex and Life
}

\author{
Gavin P Vinson
}

School of Biological and Chemical Sciences, Queen Mary, University of London, Mile End Road, London E1 4NS, UK.

(This is a record of the after dinner talk delivered at the Adrenal Conference, 2008 (San Francisco). It is not intended to be a review, but a commentary: the views expressed are personal, and literature references are illustrative rather than exhaustive).

\begin{abstract}
The template for our understanding of the physiological role of the adrenal cortex was set by Hans Selye, who demonstrated its key involvement in the response to stress, of whatever origin, and who also introduced the terms glucocorticoid and mineralocorticoid. Despite this, from the late 1940s on there was certainly general awareness of the multiple actions of glucocorticoids, including effects on the thymus and immune system, cardiovascular system, water balance, and the CNS. For these reasons, and perhaps because in the early studies of the actions of individual steroids there was less clear-cut difference between them, there was some initial resistance to the use of these terms. Today they are universal and unchallenged.

It can be argued that, with respect to the glucocorticoids, this term colours our perception of their physiological importance, and may be misleading. By taking evidence from disease states, emphasis is placed on extreme conditions that do not necessarily reveal normal physiology. In particular, evidence for the role of glucocorticoid regulation of gluconeogenesis and blood glucose in the normal subject or animal is inconclusive. Similarly, while highly plausible theories explaining glucocorticoid actions on inflammation or the immune system as part of normal physiology have been presented, direct evidence to support them is hard to find. Under extreme conditions of chronic stress, the cumulative actions of glucocorticoids on insulin resistance or immunocompromise may indeed seem to be actually damaging.

Two well documented and long recognized situations create huge variation in glucocorticoid secretion. These are the circadian rhythm, and the acute response to mild stress, such as handling in the rat. Neither of these can be adequately explained by the need for glucocorticoid action, as we currently understand it, particularly on carbohydrate metabolism or on the immune system. Perhaps we should re-examine other targets at the physiological level. At the present time, some of these seem to be out of fashion.
\end{abstract}

\section{Introduction and history}

I'm deeply honoured to be asked to give this talk.

It is about 50 years ago that I started to take an active interest in the adrenal cortex, and about 25 years since I started attending this biennial Adrenal Conference, the inspired creation of Alastair Brownie, which continues to attract and refresh the minds and imaginations of young recruits and old fogies alike. 
It's because of this history that I feel the statement I now make may seem embarrassingly naïve and ignorant. That is, that while I have learnt, one way or another, a great deal about what the adrenal cortex does (and perhaps forgotten more), I don't really know what the adrenal cortex is for. I'll qualify that, aldosterone has a beautifully clear function, in the regulation of sodium homeostasis, that alone explains the mortal danger of not having an adrenal. But aldosterone is a minor product: the major products, the glucocorticoids come from the major part of the gland, fasciculata/reticularis. I remind you that in humans there's about a thousand times more circulating cortisol than aldosterone. It's this I don't understand.

That's a real pity. Seventy years ago, or thereabouts, people really thought they were beginning to understand what the adrenal cortex is for. They were told by Hans Selye, among others. Hans Selye, as we were reminded in a recent FASEB J Editorial [1], pursued two careers, in experimental pathology and in public relations, with great success in both. Selye recognized that many quite different nocuous stimuli evoked essentially similar physiological and pathological responses in the stressed individual, including in the adrenal cortex and medulla [2,3]. This gave rise to his concept of the "General Adaptation Syndrome", and the notion that the adrenal cortex as well as the medulla has a role in stress management. It is interesting to follow the observations and logical inferences that led to these conclusions. At this time it was already known that adrenocortical hormones had actions both on electrolyte and carbohydrate metabolism, through the pioneering work of others who used adrenocortical extracts ("cortin") or as they became available, the steroids themselves. Selye's General Adaptation Syndrome fell into stages. Stage 1, the alarm reaction is the sum of all non-specific systemic phenomena elicited by sudden exposure to adverse stimuli, Stage 2 is the stage of resistance, and the reestablishment of homeostasis, and Stage 3 is the stage of exhaustion, during which the non-specific responses are no longer able to maintain homeostasis. Associated with the development of the syndrome, there are highly characteristic pathological changes in various tissues, including the pancreas, gut, kidney, liver, heart and vasculature, thymus, and crucially, the adrenal cortex. At the same time, there are changes in blood glucose and liver glycogen, and blood electrolytes. Since in addition (a) adrenocortical hormones are increased in stress (b) adrenalectomised animals have an impaired response to stress, and (c) administration of cortical hormones or extracts ameliorates the deficiencies, the connection between the adrenal cortex and the stress response became clear. This was a remarkable achievement and feat of induction and interpretation, which has left its permanent imprint on the field. Selye's full description applies to chronic and severe stress: it was noted by Fuller Albright that its features reflect those of Cushing's syndrome [4].

It was about the same time that the nature of the adrenocortical secretory product was being revealed, through bioassay and through elucidation of chemical structure. Two adrenocortical steroids available for experiment at the time of Selye's 1946 papers were corticosterone and deoxycorticosterone. It is primarily because of their different properties that Selye distinguished between "salt active" and "sugar active" adrenal steroids [3], for which, in the same year, he introduced the terms "mineralo-corticoid" and "gluco-corticoid" [5]. These terms (minus the hyphens) have stayed with us: others he introduced at the same time have not, for obvious reasons (see Table 1). 
It was clearly felt by some that in some ways that even this limited nomenclature is unfortunate, and perhaps misleading with regard to the primary roles of cortisol and corticosterone. At the same time that Selye was making his mark, the groups of Kendall and Reichstein were engaged in other epochal discoveries, in isolating from adrenocortical extracts $\sim 30$ steroids in crystal form, which were characterized both chemically and biologically, and the therapeutic value of the glucocorticoids in inflammation was revealed by Hench. It is noteworthy that in their 1950 Nobel lectures, published in 1951, none of these three laureates used either of the terms "mineralocorticoid" or "glucocorticoid" [6-8]. One may speculate there are several possible reasons for this, including the facts that of the active compounds they isolated, most showed both mineral and carbohydrate effects, though to varying degrees, moreover by this time their actions were known to be of much wider physiological significance than these narrow definitions suggest. Furthermore, the symptoms of adrenocortical insufficiency or Addison's disease could be completely reversed by administration of just one adrenal steroid (albeit in high concentrations). This single compound, by the way, was cortisone.

In this quite remarkable age of the adrenal cortex then, another group of studies completes the set, it established all of the activities of cortisone, which (if we take cortisone's actions to be attributable to its rapid conversion to cortisol) stands with very little addition to the present day. These actions were summarized in a review by Dwight $\mathbf{J}$ Ingle, in 1950 [9], and in broad outline they are listed in Table 2. This represents a phenomenal achievement by the whole field over such a short period.

It is to Ingle too that another term is due, that perhaps somewhat takes the gloss off the wonder hormone concept - "permissive" actions. Within the next few years, it had become clear that not all the actions of cortisone/cortisol were straightforward, and clear dose/response relationships were not always apparent. "Permissive" was used as an adjective with specific application to these effects of cortisone/cortisol, to indicate their actions at basal levels which are necessary to "permit" full expression of the effects of other agents [10]. In fact Ingle was somewhat defensive about the term, he wrote "It is still believed by me, and some other protagonists of the concept of permissiveness that this is a valid although admittedly superficial explanation for some causal relationships" [10]. Today I find it a less than satisfactory concept - why is the corticosteroid "permissive" whereas the other agents are the active principles, and not the other way around? While "potentiation" suggests itself as an alternative, "synergistic" is surely an even better descriptor that is certainly more consistent with contemporary knowledge of the mechanisms of hormone action. The term established itself nonetheless, and indeed encouraged further classification of the adrenal steroids, by Nelson, who distinguished qualitatively between the glucocorticoids, mineralocorticoids and androgens, and quantitatively considered all of their actions to be (in increasing concentrations) permissive, protective or pernicious! [11].

\section{Roles of glucocortioids}

Thus the terms "glucocorticoid" and "mineralocorticoid" were by this time firmly embedded, and I suggest that at least in regard to the first, rather impose a misleading expectation of the roles of these hormones. Certainly, if we examine 
what is currently being taught to undergraduate students under the heading "Actions of glucocorticoids" (and this is not difficult to establish - sufficient numbers of powerpoint presentations on this topic are easily accessed on the web), then the list of topics generally looks something like this:

1. Metabolism - primarily carbohydrate metabolism, including gluconeogenesis and increasing blood glucose (opposition to insulin) but with reference to lipid and protein metabolism as well.

2. Immune system, inflammation

3. Cardiovascular and GFR

4. $\mathrm{CNS}$

5. Development, growth, epithelia, surfactant

Something according to this pattern is fairly universal, and at least as far as the first two items is concerned, inevitable: the first because of the need to explain the nomenclature, and because classically carbohydrate metabolism has always been put as the first function, and the second, because it is as anti-inflammatories, and immunosuppressants that the glucocorticoids are mostly applied.

In fact the earlier authors were not always so convinced.

Objections to the term "glucocorticoid" were first raised by Ingle. He wrote [9]:

"At a time when the physiology of the adrenal cortex seemed more simple, cortisone and related 11-oxygenated steroids were tagged as " $S$ " or sugar hormones" or "glucocorticoids"

The author is not without sin in this matter of describing an elephant by the shape of its tail

This is an appropriate time to abandon the concept that cortisone is concerned principally with carbohydrate metabolism, and to explore each of its many biologic properties in search for new concepts of its action"

Later, Beck \& McGarry wrote [12]:

"The most important physiological actions of cortisol appear to be concerned with the distribution of body-water and electrolyte, maintenance of blood pressure and $G F R$, and the renal regulation of water excretion. At present it would seem that the term glucocorticoid is a misnomer, since the evidence available suggests that the role of cortisol in carbohydrate metabolism is a relatively minor one."

So, what exactly is the normal role of glucocorticoids in carbohydrate metabolism? - and can we yet be sure that they have one (in normal physiology, I'm not dealing with disease or extreme states here)?

\footnotetext{
${ }^{1}$ The "S" designation comes from another classification in which adrenal hormones were designated " $\mathrm{S}$ " for sugar, or " $\mathrm{N}$ " for nitrogen metabolism-regulating hormones. "N" hormones are anabolic, thus thought to be adrenal androgens [4] F. (1943) Cushing's syndrome. Harvey Lectures Series 38, 123-186.

Albright,
} 
It depends who you ask, and, if you're a student, it depends on whose lectures you attended (or whose exam you're sitting). If you are an endocrinologist, you probably tell your students that yes, glucocorticoids have a role. If you're a biochemist, you may very well not do so. Basic biochemistry texts (e.g. the contemporary versions of the biochemistry classics, Lehninger or Stryer) $[13,14]$ may have several pages on the regulation of gluconeogenesis for example, that do not mention the words "corticosteroid" "glucorticoid" or "adrenal cortex" at all.

The same dichotomy of views is found at the research level as well. For example, in a recent review, Vegiopoulos and Herzig [15] point our that more than 50 genes seem to be direct, regulatory targets of glucocorticoid action. Much of their discussion is concerned with hepatic glucose metabolism and gluconeogenesis, often considered the primary glucocorticoid-regulated processes. The definition of the precise quantitative role of the glucorticoids in physiological terms is very difficult to assess, though some have tried [16]. If we examine a key regulatory gluconeogenic enzyme, for example phosphoenolpyruvate carboxykinase (or PEPCK), then the complexity of its gene promoter explains why. There are response elements to innumerable hormone receptors, e.g. insulin, thyroid, RAR, LXR, PPAR in and around the glucocorticoid response unit, as well as for those outside it, for example Fos/Jun, NF-1, CREB/CREM [17,18]. And, at the risk of gross oversimplification, this is virtually (a qualifier only added because its always possible to miss something) always true of glucocorticoid actions in metabolism, or on metabolic enzymes. Glucocorticoids in other words may be important, even essential, but they aren't the only, or even the main drivers. Here then is the origin of the "permissive" nature of glucocorticoid actions, it lies in their synergy with many other factors [16]. This intangibility of glucorticoid actions, the way it slips through the fingers has been commented on by others [19]. How essential are the glucocorticoids in the process of PEPCK gene transcription? Clearly, some transcription may take place in their absence (see e.g. ref [18], though note this author's emphasis on glucocorticoid importance). But under what circumstances is this sufficient, and when are glucocorticoids necessary? Certainly too, prior adrenalectomy reduces and dexamethasone restores gluconeogenesis and glucose release in isolated perfused liver from fasted rats [20]. How does this relate to normal physiology? Note that these studies and reviews are largely concerned with the molecular and cellular actions of the corticosteroids.

In fact, at the physiological level, other authors rather dismiss glucocorticoids. For example, two reviews on the regulation of hepatic glucose metabolism uptake and release brush glucocorticoids aside in a sentence or two [19,21], Similarly, another review actually entitled "Hepatic glucose uptake, gluconeogenesis and the regulation of glycogen synthesis" contains no mention of adrenal cortex, cortisol, corticosteroids or glucocorticoids at all [22].

The second major group of glucocorticoid actions that endocrinology instructors tell their students about, the anti-inflammatory and immunosuppressive effects, are equally problematic. The regulation of immunity is many times more complex even than gluconeogenesis. However, the effects of administered corticosteroids have always been recognized as startling, in the reduction of inflammation and the immune response. Indeed, these have always been the greatest therapeutic application for corticosteroid drugs. Because of its complexity, however, the regulation of immunity too is a question of integration of the response to 
glucocorticoids into a huge panoply of regulatory factors, including multiple inflammatory mediators and cells, both by transactivation of anti-inflammatory agents, and transrepression of e.g. cytokines and adhesion molecules [23].

For a considerable time there was controversy about whether the actions of the glucocortioids represented physiological activity at all, but were instead purely pharmacological phenomena. Certainly the mechanisms by which corticosteroids protect against stress always seemed obscure and intangible [11].

It was Munck who first developed a physiological context. To paraphrase his concepts somewhat tersely, the hypothesis is that glucocorticoids attenuate the defence mechanisms to stress, infection, tissue damage etc that are activated by agents such as prostaglandins and lymphokines, thus preventing a dangerous level of "overshoot" that may induce even more damage [24-26]. This is a creative and thought-provoking contribution that is, however, difficult to substantiate evidentially. What is a damaging level of prostaglandin response to stress? - and what is the glucocorticoid-mediated tolerable level? Does achievement of a tolerable level of defence then feedback on the hypothalamus to limit the production of $\mathrm{CRF} / \mathrm{ACTH} /$ cortisol? How can we test that this is in fact what is happening?

Indeed, there are two specific considerations that suggest to me that this theory can only be partly true. The first relates to the Waterhouse-Friedrichsen syndrome. In this syndrome, characteristically associated with meningococcal septicaemia (but which may also arise as a complication of sepsis caused by other organisms) fever, myalgia and other symptoms are followed by haemorrhagic necrosis of the adrenal. The actions of ACTH on the adrenal vasculature are well known [27], and It was Selye who first proposed that this necrosis is attributable to excess stimulation of the adrenal [3]. Indeed, we showed that excess ACTH stimulation can bring about disruption of the sinusoids that pass through the adrenal of the rat, with extravasation of blood cells and necrosis of the adrenal tissue [28]. Here then is a classical example of a stress situation that results in an extreme demand for corticosteroid, but in which the provision of corticosteroid is inevitably compromised because the adrenal is necrotic. A condition, in other words, that appears to demand glucocortioid therapy. How ironic then that at about the same time that Munck was publishing his theory, use of corticosteroids in the Waterhouse-Friedrichsen syndrome was being abandoned after several studies showed it had no benefit (see [29] for review). The debate continued, and although it does now seem to be accepted that corticosteroid administration does have a place in the treatment of sepsis, it is astonishing that the matter remained open to debate, so long after Selye [29].

The second reservation regarding Munck's hypothesis relates to thymolysis again an effect of chronic stress that was well described by Selye. The actions of corticosteroids on the thymus are astonishingly sensitive: the thymus in young animals can be made to virtually disappear [30-32]. Selye didn't know what the function of the thymus is, at that time it was thought vaguely that it might be the source of another hormone: it was not until 1961 that its role in producing $\mathrm{T}$ lymphocytes was established [33], see [34] for review. The paradoxical effect of stress, or excess glucocorticoid is thus to eliminate an essential source of immunityconferring cells - seemingly permanently, generally the involuted thymus does not regenerate (e.g. [35]).

This appears to compound the "pernicious" concept of glucocorticoid action in stress. Not only do glucocorticoids induce symptoms similar to Cushing's syndrome, including induced insulin resistance, they may also permanently impair immunity (cf . [3,4,11]). 


\section{Triggers of glucocorticoid secretion}

The stimuli of glucocorticoid secretion extend the enigma. In the case of aldosterone by contrast, the physiological demands (for example) of a low sodium diet, or haemorrhage, are clear, and the action of aldosterone in correcting the deficit is obvious. In the case of the glucocorticoids there are two main physiological drivers, stress, of whatever origin, and the clock. These give us little or no clue about why there is a demand for glucocorticoid secretion - we can speculate, but we can hardly do more.

I take two examples from the literature to illustrate this point, one human, the other in the rat. Both of these can be taken as representative of the literature in general.

In the first case, van Cauter and co-workers put healthy volunteers into a fairly demanding situation in which they were constantly infused with glucose, but did not eat over a 36 hour period [36]. They slept roughly between midnight and 6 am for the first night, but were kept awake the second night, and only allowed to sleep at midday on the third day. Despite the constant infusion of glucose, blood glucose levels showed significant changes, with a large increase after the onset of sleep in both sleep periods. Insulin secretion, and blood levels, were closely tied to blood glucose, as expected, and the spike in GH secretion that marked the start of the sleep period was assumed by the authors to be the signal for increased blood glucose. Cortisol, in contrast, rigorously observed clock time, with peaks at about 8-10 am on both days. Thus it was only circulating cortisol that showed complete indifference to the sleep and blood glucose cycle, and that obeyed only the clock. Insulin and GH, in other words, both behaved as might be expected of metabolic hormones, cortisol emphatically did not.

In the second case, Atkinson and co-workers used a sophisticated system to monitor circulating steroid in the unstressed rat [37]. Their data demonstrate something I always suspected, but never had the skills to show: the true basal level of circulating corticosterone in this species is effectively zero. Secretion and circulating concentrations are massively increased by two effectors, the clock again, with a peak in this nocturnal species at around 6- 8 pm: secretion during the whole secretory period of say $2 \mathrm{pm}$ to midnight was highly episodic. The second stimulus to increased corticosterone was mild stress, in this case of a ten minute exposure to white noise at $104 \mathrm{db}$. The stress-stimulated corticosterone period lasted perhaps 30 minutes.

\section{What is the adrenal cortex for?}

What can we deduce from these apparently totally unrelated situations requiring increased glucocorticoid secretion? Do clock-stimulated and stressstimulated glucocorticoid have the same actions in both cases? Is the primary purpose to stimulate gluconeogenesis, oppose insulin, inhibit inflammation or the immune response, support the cardiovascular system, increase membrane permeability, increase GFR, or to act on the CNS to increase appetite or to fuel the animal's undoubted anxiety and paranoia? Or none of these? Or all of them? That there is an adrenal-dependent diurnal variation in expression of genes in the liver is known - 100 
of them in fact [38]. Are the genes that are activated by mild stress the same as those started by the clock? Why?

My view is that we hardly have any greater understanding of the roles of corticosteroids, insofar as they fulfil a physiological demand, than was available to Selye. We know that the regulation of responsive genes by glucocorticoids is not often simple, and we have difficulty in developing an integrated interpretation of the multifactorial regulation of the gene coding for PEPCK, for example. Similarly, we have no techniques available to assess the integrated significance of 100 glucorticoid sensitive genes in the liver, let alone the further possibility of non-genomic modes of action $[39,40]$. Selye approached the problem at the height of his career, and with a sense of euphoria apparent in his writing. Today, my view is much less clear. To me, understanding what the adrenal and glucocorticoids are for largely still presents a huge challenge for the future.

\section{References}

[1] Weissman, W. (2007) The experimental pathology of stress: Hans Selye to Paris Hilton. FASEB Journal 21, 2635-2638.

[2] Selye, H. (1936) A syndrome produced by diverse nocuous agents. Nature $138,32$.

[3] Selye, H. (1946) The general adaptation syndrome and the diseases of adaptation. J Clin Endocrinol Metab 6, 117-230.

[4] Albright, F. (1943) Cushing's syndrome. Harvey Lectures Series 38, 123-186.

[5] Selye, H. and Jensen, H. (1946) The chemistry of the hormones. Annual Review of Biochemistry 15, 347-360.

[6] Hench, P.S. (1951) The reversibility of certain rheumatic and non-rheumatic conditions by the use of cortisone or of the pituitary adrenocorticotropic hormone. In: Les Prix Nobel, pp. 311-341, P.A. Norstedt \& söner, Stockholm.

[7] Kendall, E.C. (1951) The development of cortisone as a therapeutic agent. In: Les Prix Nobel, pp. 270-288, P.A. Norstedt \& söner, Stockholm.

[8] Reichstein, T. (1951) Chemistry of the adrenal cortex hormones. In: Les Prix Nobel, pp. 291-308, P.A. Norstedt \& söner, Stockholm.

[9] Ingle, D. (1950) The biologic properties of cortisone: a review. J. clin. Endocr. $10,1312-1354$.

[10] Ingle, D. (1960) Role of the adrenal cortex in pathogenesis. In: Clinical Endocrinology (Astwood, E., ed.), Grune \& Stratton, New York.

[11] Nelson, D.H. (1962) Relative merits of the adrenocortical steroids. Annual Review of Medicine 13, 241-248.

[12] Beck, J.C. and McGarry, E.E. (1962) Physiological importance of cortisol. British Medical Bulletin 18, 134-140.

[13] Nelson, D.L. and Cox, M.M. (2008) Lehninger Principles of Biochemistry, W.H.Freeman \& Company, New York.

[14] Berg, J.M., Tymoczko, J.L. and Stryer, L. (2007) Biochemistry, W.H. Freeman \& Company, New York.

[15] Vegiopoulos, A. and Herzig, S. (2007) Glucocorticoids, metabolism and metabolic diseases. Mol Cell Endocrinol 275, 43-61.

[16] Exton, J.H., Blackmore, P.F., El-Refai, M.F., Dehaye, J.P., Strickland, W.G., Cherrington, A.D., Chan, T.M., Assimacopoulos-Jeannet, F.D. and Chrisman, T.D. (1981) Mechanisms of hormonal regulation of liver metabolism. Adv Cyclic Nucleotide Res 14, 491-505. 
[17] Nizielski, S.E., Lechner, P.S., Croniger, C.M., Wang, N.D., Darlington, G.J. and Hanson, R.W. (1996) Animal models for studying the genetic basis of metabolic regulation. J Nutr 126, 2697-708.

[18] Cassuto, H., Kochan, K., Chakravarty, K., Cohen, H., Blum, B., Olswang, Y., Hakimi, P., Xu, C., Massillon, D., Hanson, R.W. and Reshef, L. (2005) Glucocorticoids regulate transcription of the gene for phosphoenolpyruvate carboxykinase in the liver via an extended glucocorticoid regulatory unit. J Biol Chem 280, 33873-84.

[19] Nordlie, R.C., Foster, J.D. and Lange, A.J. (1999) Regulation of glucose production by the liver. Annu Rev Nutr 19, 379-406.

[20] Exton, J.H., Friedmann, N., Wong, E.H., Brineaux, J.P., Corbin, J.D. and Park, C.R. (1972) Interaction of glucocorticoids with glucagon and epinephrine in the control of gluconeogenesis and glycogenolysis in liver and of lipolysis in adipose tissue. J Biol Chem 247, 3579-88.

[21] Cherrington, A.D. (1999) Banting Lecture 1997. Control of glucose uptake and release by the liver in vivo. Diabetes 48, 1198-214.

[22] Radziuk, J. and Pye, S. (2001) Hepatic glucose uptake, gluconeogenesis and the regulation of glycogen synthesis. Diabetes Metab Res Rev 17, 250-72.

[23] Barnes, P.J. (2006) Corticosteroids: the drugs to beat. Eur J Pharmacol 533, 214.

[24] Munck, A., Guyre, P.M. and Holbrook, N.J. (1984) Physiological functions of glucocorticoids in stress and their relation to pharmacological actions. Endocr Rev 5, 25-44.

[25] Munck, A. and Guyre, P.M. (1986) Glucocorticoid physiology, pharmacology and stress. Adv Exp Med Biol 196, 81-96.

[26] Munck, A. (2005) Glucocorticoid receptors and physiology: a personal history. Steroids 70, 335-44.

[27] Vinson, G.P., Pudney, J.A. and Whitehouse, B.J. (1985) The mammalian adrenal circulation and the relationship between adrenal blood flow and steroidogenesis. J.Endocr. 105, 285-294.

[28] Pudney, J., Price, G.M., Whitehouse, B.J. and Vinson, G.P. (1984) Effects of chronic ACTH stimulation on the morphology of the rat adrenal cortex. Anat.Rec. 210, 603-615.

[29] Prigent, H., Maxime, V. and Annane, D. (2004) Clinical review: corticotherapy in sepsis. Crit Care 8, 122-9.

[30] Scollay, R. and Shortman, K. (1983) Thymocyte subpopulations: an experimental review, including flow cytometric cross-correlations between the major murine thymocyte markers. Thymus 5, 245-95.

[31] van Vliet, E., Melis, M. and van Ewijk, W. (1986) The influence of dexamethasone treatment on the lymphoid and stromal composition of the mouse thymus: a flowcytometric and immunohistological analysis. Cell Immunol 103, 229-40.

[32] Vinson, G.P., Whitehouse, B.J. and Hinson, J.P. (1992) The adrenal cortex, Prentice-Hall, Englewood Heights,NJ.

[33] Miller, J.F. (1961) Immunological function of the thymus. Lancet 2, 748-9.

[34] Guidos, C. (2006) Thymus and T-lymphocyte development: what is new in the 21st century? Immunol Rev 209, 5-9.

[35] Taub, D.D. and Longo, D.L. (2005) Insights into thymic aging and regeneration. Immunol Rev 205, 72-93. 
[36] Van Cauter, E., Blackman, J.D., Roland, D., Spire, J.P., Refetoff, S. and Polonsky, K.S. (1991) Modulation of glucose regulation and insulin secretion by circadian rhythmicity and sleep. J Clin Invest 88, 934-42.

[37] Atkinson, H.C., Wood, S.A., Kershaw, Y.M., Bate, E. and Lightman, S.L. (2006) Diurnal variation in the responsiveness of the hypothalamic-pituitaryadrenal axis of the male rat to noise stress. J Neuroendocrinol 18, 526-33.

[38] Oishi, K., Amagai, N., Shirai, H., Kadota, K., Ohkura, N. and Ishida, N. (2005) Genome-wide expression analysis reveals 100 adrenal gland-dependent circadian genes in the mouse liver. DNA Res 12, 191-202.

[39] Wanner, A., Horvath, G., Brieva, J.L., Kumar, S.D. and Mendes, E.S. (2004) Nongenomic actions of glucocorticosteroids on the airway vasculature in asthma. Proc Am Thorac Soc 1, 235-8.

[40] Urbach, V., Verriere, V., Grumbach, Y., Bousquet, J. and Harvey, B.J. (2006) Rapid anti-secretory effects of glucocorticoids in human airway epithelium. Steroids 71, 323-8. 
Table 1. Selye's nomenclature:

Adrenal products

Mineralo-corticoids

Gluco-corticoids

Lipo-corticoids

Testoids
Pituitary trophic factors

Mineralo-corticotrophins

Gluco-corticotrophins

Lipo-corticotrophins

Testo-corticotrophins

Selye, H. \& Jensen, H. (1946) The chemistry of the hormones. Ann Rev Biochem., 15, 347-360 [5] 


\section{Actions of cortisone}

Dwight J Ingle (1950) J clin Endocr, 10, 1312-1354 [9]

Maintenance of life

(in adrenalectomised dogs) - 1/500 as active as amorphous fraction

Ability to work (weighted gastrocnemius muscle contraction: Ingle test, also improved muscle work in Addison's patients, contrast Cushing's)

Ability to resist other stress

Protects against typhoid vaccine/ egg white anaphylaxis

Electrolyte /water metabolism

Temporary increase in sodium, chloride and potassium excretion (1-3 days - only

effect on potassium persists)

Blocks sodium retaining/potassium excreting action of DOCA

Circulation

maintains circulatory adequacy in adrenalectomised dogs after trauma, surgery or haemorrhage. Slight depressor effect in hypertensive patients

\section{Membrane permeability}

increased

Growth

Small doses increase, larger doses inhibit in young adrenalectomised rats. Temporary negative nitrogen balance.

\section{Direct applications}

Cessation hair growth, epidermal thinning, changes in fibroblasts

Delayed wound healing

Inhibition of tumour growth

Carbohydrate metabolism

Diabetogenic

Insulin resistance

Increased glycogen deposition

Fat metabolism

Ketonuria

Fat deposition - both increases and decreases recorded

Intermediary metabolism

Liver argininase increased, changes in tissue amino acid composition

Specific tissues

Thymolytic, lymphocytopenia, eosinopenia ( $3 \mu \mathrm{g}$ gives

$96 \%$ reduction in 4 hours in adrenalectomised mice),

Reduction in antibodies in immunized rabbits

increased thyroid weight 


\section{CNS}

Increased brain excitability, induction of euphoria in Addisonian patients, but longer periods may produce depression, increased appetite

\section{Reproduction}

Some decline in testis, ovarian weight in animals. Lactation restored in adrenalectomised rats

Loss of libido in men, some induction of amenorrhea in women

\section{Kidney}

Restores kidney function (i.e. excretion of urea) in adrenalectomised dog Increase PAH secretion

\section{Pituitary}

Inhibits ACTH secretion

\section{Tissue damage}

reported in cardiac \& skeletal muscle, pyloric and caecal ulcers in rats (cortisol), necrosis in liver,

Therapeutic uses

Addison's, rheumatoid arthritis, .....neoplastic diseases 